\title{
Life adaptation in 35 adults with sex chromosome abnormalities
}

\author{
Bruce G. Bender, PhD ${ }^{1,2}$, Mary G. Linden, $M S^{1}$, and Robert J. Harmon, $M D^{2}$
}

\begin{abstract}
Purpose: This report from the last phase of the 36-year Denver Study provides information about the adult life adaptation of 35 men and women with sex chromosome abnormalities (SCA) followed since their identification at birth. Methods: Sex chromatin screening of 40,000 consecutive newborns between 1964 and 1974 resulted in the cohort of 35 SCA men and women followed to date since birth. Sixteen chromosomally normal siblings served as controls. Data constituting this report was obtained from formal and informal interviews and psychological testing conducted in the final year of this study. Results: The nonmosaic SCA propositi had lower mean intelligence quotients and psychosocial adjustment scores than did siblings. Consistent with these results, propositi also had lower levels of educational achievement and career success, although most have completed school, married, hold full-time employment, and are financially independent. Conclusions: While the SCA adults demonstrated lower levels of cognitive and psychosocial competence, their overall adaptation has been positive, particularly given an early literature suggesting a high rate of psychopathology and severe dysfunction. Genetics in Medicine, 2001:3(3):187191.
\end{abstract}

Key Words: sex chromosome abnormalities, adult adaptation

The Denver Study of Sex Chromosome Abnormalities (SCA) began in 1964 with the objective of determining the frequency with which these conditions occur. ${ }^{1}$ Results from this and other epidemiological studies established a surprisingly high incidence of 1 in 400 newborns with the addition, deletion, or structural variation of an X or Y chromosome, ${ }^{2}$ making SCA the most frequently occurring chromosome abnormality. Four nonmosaic karyotypes were most common: 47,XXY; 45,X; 47,XXX; and 47,XYY. SCA mosaicism, consisting of two or more populations of cells varying in $\mathrm{X}$ and $\mathrm{Y}$ chromosome constitution, was similarly frequent.

The investigation of these conditions has not proceeded without controversy. Early chromosome screening studies established an increased incidence of SCA in prison, mental, and mental-penal populations, suggesting that the presence of SCA brought significant risk for psychopathology and antisocial behavior. ${ }^{3,4}$ Because of the selection bias inherent in these studies, debate ensued as to their accuracy. ${ }^{5}$ The need for accurate information about SCA was heightened by its representation in $25 \%$ of prenatally diagnosed chromosome disorders. ${ }^{6}$ Clearly, little was known about the natural life course of the population of individuals with these conditions.

The Denver Study and six other longitudinal research programs that followed children with SCA have provided a more

\footnotetext{
From the ${ }^{1}$ National Jewish Medical and Research Center and ${ }^{2}$ University of Colorado Health Sciences Center, Denver, Colorado.

Bruce G. Bender, PhD, National Jewish Medical and Research Center, 1400 Jackson Street, Denver, CO 80206

Received: December 6, 2000.

Accepted: January 31, 2001
}

balanced picture of the influence of SCA on the developing child, adolescent, and adult, and overall have produced a less pathologic portrayal than that emerging from the early studies of incarcerated adults. ${ }^{2,7-14}$ This report from the last phase of the 36-year Denver Study provides information about the adult life adaptation of 35 SCA men and women, now 26 to 36 years of age, followed since their identification at birth.

\section{METHODS}

\section{Subjects}

The SCA propositi were identified through the sex chromatin screening of 40,000 consecutive Denver newborns between 1964 and $1974 .{ }^{1}$ Chromosomal abnormality revealed through the examination of Barr bodies from amniotic membranes was subsequently confirmed by chromosome analysis of peripheral blood cells. Because cytogenetic techniques for identification of the smaller Y chromosome were not available until well into the 10-year chromosome-screening program, few 47,XYY infants were identified; hence, no 47,XYY men were included in this study. Sixty-three infants with abnormalities involving the $\mathrm{X}$ chromosome were identified; of these, 8 died in the neonatal period and 14 were unavailable for follow-up. Previous reports have documented the development of this cohort through infancy, ${ }^{5,15}$ childhood, ${ }^{15-18}$ and adolescence. ${ }^{7,19}$ Thirty-five of the remaining 41 propositi and 16 sibling controls have been followed into adulthood. (Six propositi were unavailable for follow-up in adulthood. Three of these were men with a 47,XYY karyotype, no longer included in this study, and three had moved from the area.) 


\section{Procedures}

Participants visit the study annually. A semistructured interview, a structured psychiatric interview, and cognitive testing were included in the final adult protocol.

1. Recurrent, semistructured interviews. The life events and experiences of participants were discussed at every contact with study personnel. Results included in this report are from the final set of interviews with participants. In order to obtain information about the life progress of participants, the following specific content areas were addressed:

a. Educational progress. Formal education, which has been completed by most participants, was documented.

b. Relationships. Information was obtained about samesex and opposite-sex relationships, including girlfriends and boyfriends, marriage, and divorce.

c. Employment. The nature and length of employment was documented.

d. Problems. Discussions included problems related to relationships, education, employment, and psychological symptoms, including anxiety and depression.

e. Leisure activity. Personal choices for pastimes and pleasures were documented.

2. A 90-minute, structured psychiatric interview. The study team psychiatrist conducted this interview with emphasis upon the following:

a. Perceptions of the adult concerning educational and occupational functioning, personal relationships, sense of self, and future plans.

b. Sexual identity including sexual relationships and orientation.

c. Psychiatric events, including medical and legal problems, significant psychological regression or breakdown, current psychiatric symptoms, drug and alcohol use and abuse, and trauma history.

d. An assessment of overall functioning and adjustment, including assignment of a Global Assessment of Functioning (GAF) score. ${ }^{20}$ This scale is coded from 1 to 90 (best) in 10-point increments and is considered a psychological, social, and occupational functioning index on a continuum of mental health/illness.

3. The Wechsler Adult Intelligence Scale-Revised. ${ }^{21}$ This test was administered and produced both a verbal and nonverbal intelligence quotient (IQ) score. These scores provided an overall assessment of intellectual competence. Both the verbal IQ score (VIQ) and the performance IQ score (PIQ) are represented on a normative distribution with a mean of 100 and standard deviation of 15.

\section{RESULTS}

Mean scores for the continuous variables are represented in Table 1 and include VIQ and PIQ, GAF score, and years of education. Frequency data for impaired GAF scores, completion of high school and college, marriage, employment, and home ownership are included in Table 2. Categories of em-
Table 1

Means \pm standard deviations for continuous variables

\begin{tabular}{cccccc}
\hline & $\begin{array}{c}\text { Age } \\
(\mathrm{yr})\end{array}$ & VIQ & PIQ & $\begin{array}{c}\text { Global } \\
\text { assessment of } \\
\text { functioning }\end{array}$ & $\begin{array}{c}\text { Years of } \\
\text { education }\end{array}$ \\
\hline $47, \mathrm{XXY}$ & 27.7 & $90.1^{a}$ & $94.9^{a}$ & 70.6 & $12.8^{a}$ \\
$n=11$ & $(2.76)$ & $(5.09)$ & $(3.86)$ & $(3.50)$ & $(0.63)$ \\
$47, \mathrm{XXX}$ & 31.1 & $78.7^{a}$ & $85.5^{a}$ & $61.1^{a}$ & $11.9^{a}$ \\
$n=11$ & $(2.55)$ & $(5.34)$ & $(4.05)$ & $(3.50)$ & $(0.63)$ \\
$45, \mathrm{X}^{b}$ & 28.5 & $87.8^{a}$ & $83.0^{a}$ & 68.9 & 13.5 \\
$n=8$ & $(2.98)$ & $(5.63)$ & $(4.27)$ & $(4.10)$ & $(0.74)$ \\
Mosaic $^{c}$ & 30.2 & 101.7 & 104.0 & 82.0 & 13.6 \\
$n=5$ & $(2.59)$ & $(6.89)$ & $(5.23)$ & $(5.19)$ & $(0.93)$ \\
Sibling controls $^{d}$ & 28.3 & 105.7 & 109.9 & 77.3 & 14.1 \\
$n=16$ & $(4.42)$ & $(4.36)$ & $(3.31)$ & $(2.90)$ & $(0.52)$ \\
\hline
\end{tabular}

${ }^{a}$ Significantly different from sibling controls (Mann-Whitney $U$ test, $P<$ $0.05)$

${ }^{b}$ Of the eight propositae with $45, \mathrm{X}$ and variant, five were $45, \mathrm{X}$, two were $46, \mathrm{XXq}^{-}$, and one was 45,X/46,X,r(X).

${ }^{c} \mathrm{Of}$ the five female propositi with mosaicism, three were $45, \mathrm{X} / 46, \mathrm{XX}$, and one each were 45,X/47,XXX and 46,XX/47,XXX.

${ }^{d}$ The controls consisted of eight brothers and eight sisters of propositi, no more than one from any family and all with normal chromosome constitution.

ployment are detailed in Table 3. Because of small sample size and non-normal distribution of test scores, the nonparametric Mann-Whitney $U$ test was employed to determine whether group differences existed for each of the variables, with differences significantly indicated at a $P$ value of $<0.05$. Comparison of categorical data frequency counts between the same groups was completed with the Chi-square test.

\section{0}

IQ test results provide a broad measure of intellectual competence. All nonmosaic groups had lower mean VIQ and PIQ scores than the sibling control group (Table 1). The nonmosaic women achieved the lowest mean scores of all the groups. Different patterns emerged between the two groups of women, however, with 47,XXX women showing markedly lower VIQ and 45,X women markedly lower PIQ. Variability was considerable, with IQs in the nonmosaic groups ranging from 62 to 121. Notably, the highest and lowest recorded IQs both occurred in the 47,XXX group. Scores in the mosaic and sibling groups were similar to each other.

\section{GAF}

While mean GAF scores appeared to be reduced in all nonmosaic groups, they were significantly lower than sibling controls only in the 47,XXX group (Table 1). Across the nonmosaic groups, GAF scores ranged from 44 to 95 . Higher scores indicate relatively stronger psychological, social, and occupational functioning, while GAF scores below 60 indicate significant impairment of functioning. ${ }^{20}$ Eleven of 30 nonmosaic propositi had GAF scores below 60, in contrast to 1 of 16 sib- 
Table 2

Life event frequency data from final evaluation

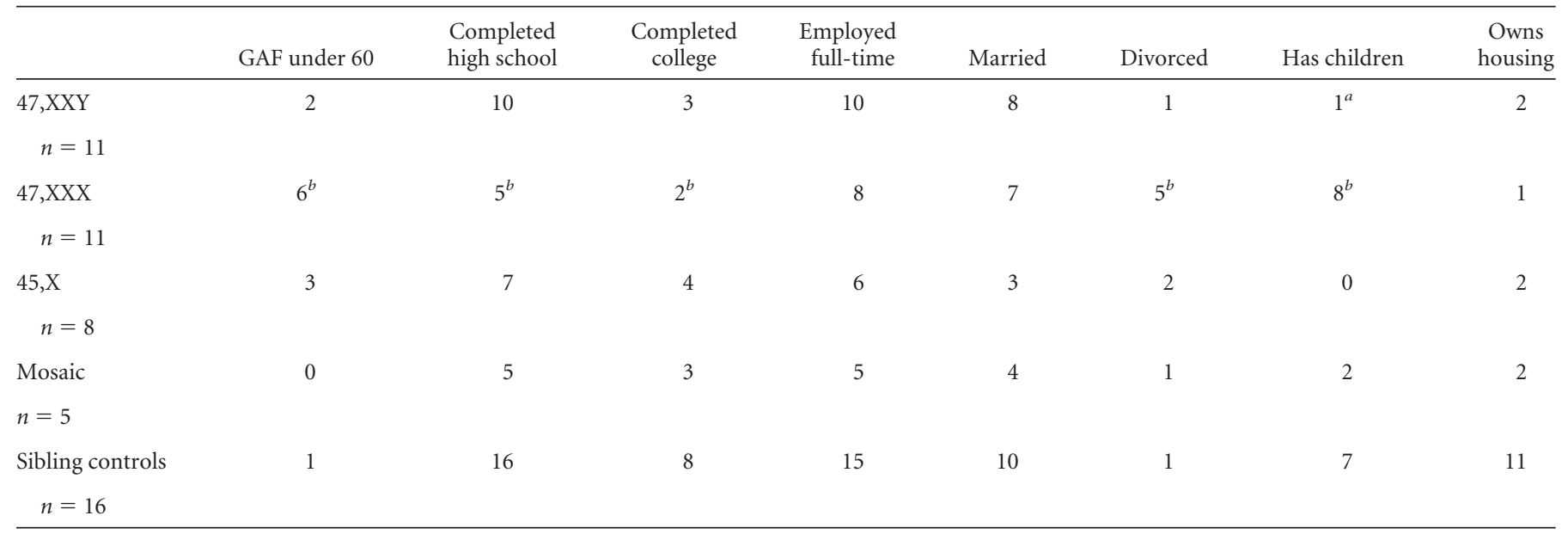

${ }^{a}$ Adopted.

${ }^{b}$ Significantly different from siblings (chi square, $P<0.05$ ).

lings. These included six 47,XXX women, three 45,X women, and two 47,XXY men. No differences emerged between the sibling and mosaic groups.

\section{Education}

Years-of-education reflects the number of years of formal education completed. A high school degree thus equals 12 years of education, regardless of whether the individual attended high school more than four years or obtained a Graduate Equivalency Degree rather than a traditional high school diploma. A college bachelor's degree equals 16 years and a master's degree is equivalent to 18 years of education.

Mean educational achievement was significantly lower than siblings in the 47,XXY and 47,XXX groups (Table 1). Twentytwo of 30 nonmosaic propositi and all siblings earned a high school degree (Table 2). One third of the nonmosaic propositi, half of the siblings, and half of the mosaic propositi earned a college degree. The lowest level of educational achievement was seen in the 47,XXX group; only five of 11 completed high school with two of these women advancing to complete a college degree.

\section{Employment}

Most of the nonmosaic propositi (24 of 30) and siblings (15 of 16) were employed full time. The employment figures in
Table 2 account only for most recent employment. One $47, \mathrm{XXY}$, three $47, \mathrm{XXX}$, two $45, \mathrm{X}$ propositi, and one sibling were unemployed at the time of follow-up. All five mosaic propositi were employed full time. Differences were seen in the nature of employment. Most of the employed 47,XXX women held unskilled or semiskilled jobs (Table 3), such as waitress or cashier, although one was an accountant. The largest portion of 47,XXY men held semiskilled and skilled positions, including mechanic and store manager. Most of the 45, X women were unemployed or employed in low-paying, unskilled jobs, but two held professional positions of nurse and social worker. The mosaic and sibling groups were distributed in the upper three employment categories from semiskilled to professional.

\section{Marriage and children}

The majority of propositi and siblings have been married (Table 2). The proportion of married individuals is highest in the sibling and mosaic groups, yet nearly two-thirds of 47,XXY men and 47,XXX women have been married. In contrast, only three of the eight 45,X women have been married. Marriage among nonmosaic propositi was more likely to end in divorce than among siblings; 8 of 18 marriages of propositi ended in divorce, in contrast to one sibling control. Eight 47, XXX women have reproduced. While the $47, \mathrm{XXY}$ men and 45, X

Table 3

Type of employment

\begin{tabular}{|c|c|c|c|c|c|}
\hline & $\begin{array}{l}47, \mathrm{XXY} \\
(n=11)\end{array}$ & $\begin{array}{c}47, \mathrm{XXX} \\
(n=11)\end{array}$ & $\begin{array}{c}45, \mathrm{X} \\
(n=8)\end{array}$ & $\begin{array}{l}\text { Mosaics } \\
(n=5)\end{array}$ & $\begin{array}{l}\text { Siblings } \\
(n=16)\end{array}$ \\
\hline No job & 1 & 3 & 3 & 0 & 1 \\
\hline Semiskilled (newspaper printing assistant, cashier, car detail) & 5 & 1 & 0 & 2 & 6 \\
\hline Skilled (bus driver, chef, store manager, mechanic, military) & 4 & 3 & 1 & 2 & 6 \\
\hline
\end{tabular}


women are infertile, one 47,XXY man has adopted a daughter (Table 2). Eleven siblings have had children.

\section{Housing}

Owning a home is a reflection of having achieved financial independence in adulthood. Seven of 30 nonmosaic propositi own homes, in contrast to 11 of 16 sibling controls (Table 2). Most nonmosaic propositi rent their home or apartment. Six nonmosaic propositi (one 47,XXY, four $47, \mathrm{XXX}$, one $45, \mathrm{X}$ ) and two siblings live with a parent or grandparent.

\section{Pastimes and pleasures}

Personal choices for recreational and leisure time activities provide an additional glimpse into the lives of participants. Both propositi and sibling controls described a wide range of interests and choices. Overall, the response to the question "How do you like to spend your free time?" was pleasure at describing individual interests. There was no consistent difference in the pastimes and pleasures between propositi and controls. Both groups reported engaging in outdoor activities, computer games, movies, family outings, and church groups. The 47,XXY men often listed noncompetitive physical activities (sailing, camping, fishing) while sibling controls, both male and female, more frequently included athletic choices (tennis, running, biking). The choices of 47, XXX and 45,X women generally included more indoor activities (cooking, church group, movies, shopping), although one 47,XXX woman reported that she enjoys camping and helping her husband race stock cars.

\section{DISCUSSION}

SCA, the most frequently occurring chromosome abnormality, is present in one out of 400 live newborns. Adults with SCA have increased risk of psychological difficulty and impaired adaptation. The nonmosaic propositi in this study, including men and women with an additional $\mathrm{X}$ chromosome and women with $\mathrm{X}$ or partial X monosomy, have on average lower levels of intelligence, psychological adaptation, educational achievement, vocational competence, and economic independence. The 47,XXX women demonstrate the greatest degree of impairment, with IQ scores approximately 20 points beneath sibling controls, and the lowest levels of psychological adaptation and educational achievement. These women have also completed fewer years of education and achieved less independence; three are unemployed, and four are living with a parent. The group of five SCA mosaics was indistinguishable from the sibling controls on any measure or marker of behavioral adaptation, suggesting that the presence of abnormal SCA cells was not sufficient to significantly alter development.

Psychological difficulty experienced by propositi was not indicative of severe psychopathology in most cases. Exceptions include two 47,XXX women, one each with histories of psychotic episodes and schizoid personality disorder, and two siblings, one male and one female, with bipolar disorder. For remaining propositi, both male and female, problems in their psychological adjustment have consisted of less severe pathology. Depression, anxiety, or substance abuse, well recognized responses when life demands exceed coping resources, ${ }^{22}$ afflict 6 of 30 nonmosaic propositi and are not specific to any one karyotype.

Most remarkable in the results from this longitudinal study is the large variability in psychological phenotypes and the adaptive accomplishments of many propositi. While comparison of mean scores on various measures allows for broad understanding of the progress of this group, attempts to typify the SCA adult seldom succeed. As suggested in the IQ range of $62-121$, abilities vary greatly. Dating back to early studies that screened chromosomes in populations of incarcerated felons and mental patients, the SCA literature tends to focus on evidence of pathological adaptation. It is the degree of normalcy, however, that we find most impressive. The majority of nonmosaic propositi have completed high school, married, hold full-time employment, and are financially independent of their parents. Nine have completed college. Few have advanced to professional employment, but eight hold levels of skilled employment including chef, store manager, and mechanic. The interests, concerns, and life challenges of propositi are similar to those of the sibling controls.

Overall adult adaptation in the group of 30 nonmosaic propositi is stronger than that seen during their adolescence, when frustration, anger, and depression were frequent. ${ }^{7}$ Numerous individuals struggled into early adulthood with a variety of problems, including erratic academic performance, frequent job changes and periods of unemployment, substance abuse, minor skirmishes with the law, and family conflict. In some cases, a desire to make positive adaptive gains has been frustrated by economic limitations. Two 47,XXX women have demonstrated improved self-awareness and judgment and share a desire to improve their lives but feel trapped in unhappy marriages, which they are unable to leave because of financial dependence and responsibility to their children.

In numerous other instances, however, propositi have overcome earlier problems, obtaining more rewarding employment, achieving financial independence, and developing more stable personal relationships. No single factor appears to have helped the individuals to make improvements in their lives, but a slowly emerging maturity in these individuals was characterized by acknowledgment of past mistakes and a desire to establish stability and independence. Pivotal events that seemed to mark the beginning of improvement were variable and included finding a previously unidentified biological father, joining a supportive religious group, moving to a small town, obtaining a better job, and entering into positive relationship resulting in marriage. Longevity in a single job has been a frequent precursor to increased stability, financial independence, and personal satisfaction. One 45,X woman, despite a long history of significant learning disability, worked diligently to complete college and a master's degree in social work.

Conclusions drawn from this study must be qualified with the realization that sample size is small. A strength of the study has been the unselected manner in which the cohort was first 
identified. Studies based upon patients who have presented themselves to physicians generally do not accurately represent the greater population of individuals sharing the same genetic defect. The screening of consecutive newborns, as occurred in the identification of the participants in this study, avoids this bias. In the absence of newborn chromosome screening studies conducted in this country after 1980, no further longitudinal information about unselected cohorts of SCA subjects is likely to be available in the foreseeable future.

\section{Acknowledgments}

This study was supported in part by grant 5RO1-HD10032 from the U.S. Public Health Service and grants MO1 RR00069 and MO1 RR00051 from the General Clinical Research Centers Program, National Center for Research Resources, National Institutes of Health.

\section{References}

1. Robinson A, Puck TT. Studies on chromosomal nondisjunction in man. II. Am J Hum Genet 1967;19:112-129.

2. Robinson A, Lubs HA, Bergsma D, editors. Sex chromosome aneuploidy: prospective studies on children. Birth Defects 1979;15.

3. Hook EB. Extra sex chromosomes and human behavior: the nature of the evidence regarding XYY, XXY, XXYY, and XXX genotypes. In: Vallet HL, Porter IY, editors. Genetic aspects of sexual differentiation. New York: Academic Press, 1979:437-463.

4. Polani PE. Abnormal sex chromosomes, behaviour and mental disorder. In: Tanner J, editor. Developments in psychiatric research. London: Hodder \& Stoughton, 1977:89-128.

5. Robinson A, Puck M, Pennington B, Borelli J, Hudson M. Abnormalities of the sex chromosomes: a prospective study on randomly identified newborns. Birth Defects 1979;15:203-241.

6. Crandall BG, Lebherz TB, Rubinstein L, Robertson RD, Sample WF, Sarti D, Howard J. Chromosome findings in 2,500 second trimester amniocenteses. Am J Med Genet 1980;5:345-356.

7. Bender BG, Harmon RJ, Linden MG, Robinson A. Psychosocial adaptation of 39 adolescents with sex chromosome abnormalities. Pediatrics 1995;96:302-308.
8. Bender BG, Harmon RJ, Linden MG, Bucher-Bartelson B, Robinson A. Psychosocial competence of unselected young adults with sex chromosome abnormalities. Am J Med Genet (Neuropsychiatr Genet) 1999;88:200-206.

9. Evans JA, Hamerton JL, Robinson A, editors. Children, and young adults with sex chromosome aneuploidy: follow-up, clinical, and molecular studies. Birth Defects 1990;26(4).

10. Harmon RJ, Bender BG, Linden MG, Robinson A. The transition from adolescence to early adulthood: adaptation and psychiatric status of women with 47,XXX. J Am Acad Child Adolesc Psychiatry 1998;37:286-291.

11. Linden MG, Bender BG, Robinson A. Intrauterine diagnosis of sex chromosome aneuploidy. Obstet Gynecol 1996;87:468-475.

12. Ratcliffe SG, Paul NP, editors. Prospective studies on children with sex chromosome aneuploidy. Birth Defects 1986;22(3).

13. Robinson A, Bender BG, Borelli J, Puck MH, Salbenblatt JA, Winter JSD. Sex chromosomal aneuploidy: prospective and longitudinal studies. Birth Defects 1986;22: 23-71.

14. Stewart DA, editor. Children with sex chromosome aneuploidy: follow-up studies. Birth Defects 1982;18.

15. Robinson A. Studies on infants and children with sex chromosomal abnormalities. In: Borek C, Fenoglio CM, King DW, editors. Cancer biology. IV. Differentiation and carcinogenesis, advances in pathobiology, No. 6. New York: Stratton Intercontinental Medical Book Corp, 1977:214-226.

16. Bender BG, Puck MH, Salbenblatt JA, Robinson A. Cognitive development of children with sex chromosome abnormalities. In: Smith S, editor. Genetics and learning disabilities. San Diego: College Hill Press, 1986:175-201.

17. Bender BG, Linden MG, Robinson A. Environment and developmental risk in children with sex chromosome abnormalities. J Am Acad Child Adolesc Psychiatry 1987; 26:499-503.

18. Robinson A, Bender B, Borelli J, Puck M, Salbenblatt J. Sex chromosomal anomalies: prospective studies in children. Behav Genet 1983;13:321-329.

19. Bender BG, Linden MG, Robinson A. Neuropsychological impairment in 42 adolescents with sex chromosome abnormalities. Am J Med Genet (Neuropsychiatr Genet) 1993;48:169-173.

20. American Psychiatric Association. Diagnostic, and Statistical Manual of Mental Disorders, 4th edition (DSM-IV). Washington, DC: American Psychiatric Association, 1994.

21. Wechsler D. The Wechsler Adult Intelligence Scale-revised manual. New York: Psychological Corporation, 1981.

22. Monat A, Averill JR, Lazarus RS. Anticipatory stress and coping reactions under various conditions of uncertainty. J Pers Soc Psychol 1972;224:237-253. 